\title{
HIV Testing And Counselling Among The Youth of Ghana: The Case Of Tarkwa-Nsuaem And FanteAkwa District
}

\author{
Theophilus Andoh-Robertson \\ University of Mines and Technology (UMaT), Tarkwa \\ P. 0. Box 237, Tarkwa, Ghana. \\ Kennedy Nyeseh Ofori \\ Wesley College of Education \\ Kumasi.
}

\begin{abstract}
This study was conducted to examine the factors that contribute to the utilization of HIV Testing and Counselling (HTC) among the youth in Ghana focusing on Fanteakwa District and Tarkwa-Nsuaem Municipality in light of the Health Belief Model. The study involved 424 youths between the ages of 15 - 24. The quantitative approach was used in the study. Multi-stage sampling technique was adopted for the study involving the purposive sampling which was used to select the two districts and then the simple random sampling method which was also used to select the communities and participants. A structured questionnaire made up of 30 items was administered to the respondents to collect data and processed using STATA 15. The results showed that majority of the respondents (over $80 \%$ ) had heard about HTC and also knew where to go for HIV testing. Again, It was also revealed from the study that as little as $\mathbf{2 5 \%}$ had ever taken HIV test at the time of the study with the males being in majority than the females. In addition, more than half of the respondents $(57.6 \%)$ have been given precounselling service before the test and majority of them $(67.3 \%)$ went back for their test results. It was also found that $\operatorname{sex}(p=\mathbf{- 0 . 5 2 8 5 4})$, place of residence $(p=\mathbf{- 0 . 6 7 8 2 4})$ of respondents and perceived susceptibility $(p=-0.07187)$ were significantly associated with HTC participation. It was recommended that social media should be used as a tool for disseminating information on HTC and also, the development and mass distribution of Self-test kits for HIV for the youth.
\end{abstract}

Keywords: HIV Testing and Counselling (HTC), Confidentiality, Persons Living with HIV and AIDS (PLWHA), Health Belief Model (HBM).

\section{Background to the study}

\section{INTRODUCTION}

The Human Immunodeficiency virus (HIV) infection and its associated pandemic of Acquired Immune Deficiency Syndrome (AIDS) have burdened the population with serious public health and socioeconomic challenges over the years. The disease does not only affect the patients' physical condition, but also affects their sociocultural relations, mental health, and financial aspects of life. HIV/AIDS was first reported in 1981 among five young men in United States of America, and since then, the human race continues to suffer huge human, economic and social losses especially in Sub-Sahara Africa as a consequence of not finding a cure or a vaccine for the disease (Tanye, 2013).

The number of persons living with HIV and AIDS in Ghana as estimated by the 2014 National HIV and AIDS Status Report was 250,232, made up of 59 percent females and 41 percent males. 
The report further indicates that, there were 21,223 children living with HIV and AIDS, and an estimated 1,295 children died annually from AIDS related illness (GAC/MOH, 2014).

The World Health Organisation-WHO (2007) and Tanye (2013) reports indicate that, more than $50 \%$ of all HIV infections worldwide are among young people aged 15-24 years and again, more than 6,000 youth are newly infected with HIV each day throughout the world. This rate of infection is due to the fact that the youth are more likely to engage in highly risky behaviours such as unprotected sexual intercourse that will lead them to contract HIV infection. Over half of the youth would have had sex by age 17 (Tanye, 2013 citing Summerfield, 2008). Interestingly, adolescents and the youth have more sexual desires and are also more likely to engage in unprotected sexual intercourse. Therefore, the youth remain at the centre of the epidemic in terms of transmission, vulnerability, impact and also potential for behaviour change. This implies that the youth will determine the course of the epidemic and therefore they are a critical focus for HIV prevention and behaviour change programmes (Tanye, 2013).

\section{Statement of the Problem}

The need for HIV Testing and Counselling (HTC) as an effective tool of prevention of HIV and AIDS among the youth cannot be underestimated. Although HIV testing has often been used as a diagnostic tool to confirm symptomatic AIDS, it is increasingly becoming difficult for most of the population, particularly the youth to go for HIV Testing and Counselling (Fiaveh \& Lakas, 2011). Hence, the intended commitment by world leaders to end the HIV and AIDS menace by the year 2030 seems to be back firing even though more persons living with HIV and AIDS appear to be on ART (UNAIDS, 2016). The potential of reducing HIV and AIDS in Ghana for example is undermined by the low patronage of testing and counselling among the youth $(21 \%$ of females and $14 \%$ of males). Even among those who utilize HTC, only $17 \%$ of females and $12 \%$ of males return for their results (Chris-Koka, 2012 citing GSS, 2010). According to Yahaya et al (2010), a study in Ghana showed that $78 \%$ of the respondents had never undergone any HIV testing and majority of the respondent were not accessing the available HTC services.

Though, there has been a persistent decline in the prevalence rate generally in Ghana, same cannot be said of Tarkwa-Nsuaem and Fanteakwa District since the prevalence rate keeps increasing over the last few years. For instance in Fanteakwa, in; 2012, 2013 and 2014 recorded $1.4 \%, 2.4 \%$ and $4.2 \%$ respectively (GAC/MOH, 2014), becoming the rural site with the highest prevalence rate in HIV Sentinel survey conducted in Ghana for the year 2014. The pattern of the disease in the District is disturbingly unpredictable and has therefore become imperative to conduct research on HIV testing and counselling among the youth in the two districts.

It is worthy to note that, Tarkwa-Nsuaem Municipality is mining area where large capital mining projects are scattered all over. Research has shown a strong correlation between the execution of large capital projects and HIV/AIDs vulnerabilities. The inhabitants' knowledge on HIV test and counselling is therefore very imperative to the control of the disease.

The critical question the study seeks to answer is: "what factors contribute to knowledge, utilization of HTC services, and severity of HIV and AIDS among the youth in Ghana?"

\section{Objectives of the Study}

The general objective of the study is to examine the factors that contribute to HIV Testing and Counselling (HTC) utilization, among the youth in Tarkwa Municipality and Fanteakwa District of Ghana in the light of the health belief model. The specific objectives of this study were to:

i. Examine the knowledge level of the youth about HTC services. 
ii. Assess the extent to which youth in Tarkwa and Fanteakwa District utilize HIV Testing and counselling services.

iii. To evaluate HIV Test and Counselling accessibility between the two districts.

\section{Research Questions}

In line with the stated objectives, the following research questions were raised:

i. To what extent do youth in Tarkwa and Fanteakwa Districts use HIV Testing and counselling services?

ii. To what extent do the youth in the districts know about the HIV/AIDs issues in the district?

iii. What socio-demographic characteristics of the youth (gender, educational level, marital status) are associated with HTC participation?

\section{Significance of the Study}

This study will offer all stakeholders in health, useful suggestions with regards to improvements in HTC services as a means of reducing the prevalence rate and impact of the HIV and AIDS pandemic among the youth irrespective of their sex, religion and educational level. The study is important because it could guide the introduction of HTC programmes and provide baseline information for evaluating the effectiveness of strategies for the prevention of HIV infection among rural and urban dwellers in Tarkwa-Nsuaem and Fanteakwa Districts.

\section{Delimitations}

This study is confined to only youths in Tarkwa-Nsuaem and Fanteakwa Districts. The study does not cover all the youth but those within the ages of 15 to 24 years. Again the study does not also cover other forms of prevention of HIV and AIDS such as Prevention of Mother to Child Transmission (PMTCT) or condom use but only HIV Testing and Counselling (HTC) services.

\section{THEORETICAL FRAMEWORK OF THE STUDY}

The purpose of the review was to explore what has been done on HIV and AIDS in relation to HIV Testing and Counselling both globally and locally, in order to situate the study in a proper perspective.

A theoretical framework is a collection of interrelated concepts, and provides guidance to research determining things to be measured as well as relationships (Phiri \& Phiri, 2016).

HIV transmission has basically been identified as an issue relating to a person's behaviour. For this reason, most behavioural theories propounded to modify the attitude of persons gives real basis for most health prevention programmes worldwide, with HIV and AIDS being no exception. King (1990) asserts that though the Western countries have been in the forefront of pioneering these psychological theories, its application and usage is spread in almost every part of the world, in spite of the difference in results often generated. Many behavioral theories and models provide useful frameworks for addressing HIV and AIDS. Five of the most commonly applied theories are the Health Belief Model, Theory of Reasoned Action, Trans theoretical Model of Behavior Change, AIDS Risk Reduction Model and Social learning Theory.

The Health Belief Model (HBM) is applied to this study due to its ability to link attitudes, beliefs, perception and knowledge directly to a person's attitude over time. Again the HBM has the tendency to recognize the significance of past experiences of persons and makes it more appropriate for what the study aims to achieve. Thus, the study is grounded on Health Belief Model (Rosenthal, Strtchem \& Bercker, 1994) as the theoretical framework because of its relevance to the study. In applying the HBM to HIV and AIDS prevention, Downing-Matibag \& 
Geisinger (2009) studied casual sexual activity among college students and verified the validity of the HBM. They concluded that, there is high likelihood that people will perform an HIV and AIDS prevention activity such as wearing condom correctly and consistently for sexual intercourse, if they believe that HIV and AIDS is a severe disease condition and they are highly susceptible to it.

\section{Research Design}

\section{RESEARCH METHODOLOGY}

A cross sectional study design was employed among youth drawn from selected communities in the Tarkwa-Nsuaem and Fanteakwa Districts for the study. Cross sectional research designs are snapshot descriptive studies of a situation at one particular time. This study design was employed due to time and financial expediency.

\section{Location of the Study}

Tarkwa-Nsuaem and Fanteakwa districts are two distinct districts with dissimilar characteristics. While Tarkwa is in the Western Region, Fanteakwa is in the Eastern Region of Ghana. Tarkwa-Nsuaem municipality has a total land area of $2,354 \mathrm{~km}^{2}$. The municipality is one of the richest in Ghana in terms of natural resources. Tarkwa is an urban area with large capital mining projects. Gold and Manganese are its major natural resources. The main occupation of the people is mining and trading. The district also has the region's only public university: - the University of Mines and Technology, Tarkwa. Fanteakwa district on the other hand is a rural community and are predominantly farmers. The main occupation of the people is farming, followed by trading. It is the third largest district in the Eastern Region in terms of land size (total land area of 1,150 square kilometres), lying within longitudes $0032.5^{\prime}$ West and latitudes 6015' North and 6010' South.

These dissimilar charateristics of the two districts however, makes them vulnerable to HIV/AIDS. It will therefore not be surprising that some of these youths get infected with HIV/AIDS. These therefore raise concerns for this study.

\section{Population}

The population for the study included all youths within the ages of 15-24 years resident in the Tarkwa-Nsuaem and Fanteakwa District of Ghana. The total population of the study area was 108,614 while the number of youths within the ages of 15-24 years was 20,186 (GSS, 2010). The target population from which the sample was drawn from was estimated to be 10,093, representing 50 percent of the entire youth from 15 to 24 years in the two Districts.

\section{Sample and Sampling Technique}

The multi-stage sampling technique was used in the study. According to Badu-Nyarko (2011), this type of technique is adopted when the researcher has to first select the population units in groups, before determining some of the units or all of the units in each group. First, purposive sampling technique was used to select the two districts out of the total 212 districts in Ghana. Then, the communities were randomly selected from the two districts to ensure a fair coverage and enhance representativeness of the findings. Later, individual respondents within the ages of 15-24 years in houses were also selected using simple random sampling technique.

\section{Sample Size Determination}

The sample size of the study was calculated using Yamane's formula, (Sarmah, Bora-Hazaika \& Cloudbury, 2013) for calculating sample size for cross- sectional study. 
Where $=\mathrm{n}$ is the sample size

$$
n=\frac{N}{1+N(\propto)^{2}}
$$

$\mathrm{N}$ is the total number of target population

$\alpha$ is the margin of error (5\%)

Thus, the sample used for the study was computed using:

$\mathrm{N}=10,093$

$\alpha=0.05$

Therefore, $n=\frac{10,093}{1+10,093(0.05)^{2}}$

$$
\begin{aligned}
& \mathrm{n}=\frac{10,093}{26.233} \\
& \mathrm{n}=385
\end{aligned}
$$

Thus, the minimum number of questionnaires administered was estimated to be 385 .

Kunsu (2010), in his study to assess the knowledge of Adolescents on HIV and HCT in Nadowli District of Ghana was emphatic that, issues on HIV and AIDS was likely to have a high drop rate due to its sensitivity, hence suggested an addition of a non-response rate. That is $10 \% \times 385=$ $38.5=\sim 39$.

Therefore, with the addition of a 10\% non-response rate, the final sample size became 424 .

Hence, a sample size of 424 young people between the ages of 15 and 24 years from the two (5) districts was used for the study. The respondents were selected randomly in each housing unit. A person of age 15 to 24 years was identified and given a questionnaire to respond. Where an identified person declined to participate, he or she was replaced by another from the same or the next sampled house.

\section{Research Instrument}

The instrument for the data collection was self-administered questionnaire. The questionnaires were made up of 30 items which were personally delivered to the participants. The questionnaire had three main sections on three (3) thematic areas including, bio-data of the respondents, Knowledge of HIV/AIDS and HTC and utilization of HTC services.

\section{Data Collection}

Quantitative data was obtained through the responses offered by the participants using structured questionnaire which were mostly closed-ended.

\section{Data Analysis}

Data collected from the survey was analysed quantitatively. The collected data was cleaned, coded, and processed using STATA computer soft-ware package version 15. Frequencies, means, standard deviation (SD) and percentage distributions were used to summarise the data and to discover the magnitude and direction of the responses.

Logistic regression analysis was also used to analyze the factors which influenced the HTC level in the Tarkwa-Nsuaem and Fanteakwa districts. The statistical software tool employed was the STATA 15. 


\section{Ethical Considerations}

In respect to this study, participants were fully informed to volunteer freely without inducement, and were also protected with regard to the anonymity and confidentiality of information they provided on the questionnaire.

Permission was obtained from household heads and all individual respondents (youth) were made to sign a consent form. For respondents who were below the age of 18 years, the consent of their parents or guardians was obtained.

\section{FINDINGS}

This part presents the results of the study. Analysis of the results are organized into three sections namely; socio-demographic characteristics of respondents, knowledge of HIV Testing and Counselling, utilization of HIV Counselling and Testing services.

\section{Demographic characteristics of Respondents}

The demographic characteristics of the respondents in terms of sex, age, place of residence, level of education, marital status and living arrangement are depicted in Table 4.1.

Table 4.1: Distribution of the demographic characteristics of respondents

\begin{tabular}{|c|c|c|}
\hline Variables & Frequency & Percentage (\%) \\
\hline \multicolumn{3}{|l|}{ Sex } \\
\hline Male & 207 & 48.8 \\
\hline Female & 217 & 51.2 \\
\hline \multicolumn{3}{|l|}{ Age } \\
\hline $15-19$ & 272 & 64.2 \\
\hline $20-24$ & 152 & 35.8 \\
\hline \multicolumn{3}{|l|}{ Place of Residence } \\
\hline Rural & 227 & 53.5 \\
\hline Urban & 197 & 46.5 \\
\hline \multicolumn{3}{|l|}{ Education Level } \\
\hline None & 39 & 9.2 \\
\hline Primary & 29 & 6.8 \\
\hline JHS & 191 & 45 \\
\hline SHS and Above & 165 & 38.9 \\
\hline \multicolumn{3}{|l|}{ Marital Status } \\
\hline Single & 205 & 48.3 \\
\hline Married & 43 & 10.1 \\
\hline Divorced & 9 & 2.1 \\
\hline Separated & 4 & 0.9 \\
\hline Widowed & 6 & 1.4 \\
\hline In a Relationship & 157 & 37 \\
\hline \multicolumn{3}{|l|}{ Living Arrangement } \\
\hline Alone & 63 & 14.9 \\
\hline With parents & 231 & 54.5 \\
\hline With friends & 10 & 2.4 \\
\hline With other relatives & 88 & 20.8 \\
\hline With spouse & 32 & 7.5 \\
\hline
\end{tabular}


From table 4.1, most of the respondents in the study (51.2\%) were made up of females while the males were made up of $48.8 \%$. In terms of age, $64.2 \%$ were between the ages of $15-19$ years while $35.8 \%$ were between the ages of 20-24 years. More than half of the respondents (53\%) included in the survey lived in the rural area whereas $46.5 \%$ lived in the urban area. In terms of level of education, the majority of the respondents (45\%) were Junior High School (JHS) leavers. Almost two-fifth (38.9\%) had received Senior High School Education and above, $6.8 \%$ had Primary education and $9.2 \%$ had no formal education. In relation to marital status, majority of the respondents (48.9\%) were single while $10.1 \%$ were married. As much as $37.0 \%$ were in a sexual relationship. Finally, those who lived with their parents constituted the majority $(54.5 \%)$ of the sampled population, followed by those who lived with other relatives $(20.8 \%)$ and nearly $15 \%$ lived alone.

\section{Level of Respondent's Knowledge on HIV Testing and Counselling (HTC)}

The first objective of the study was to examine the knowledge level of respondents about HIV Testing and Counselling. Knowledge of HIV Testing and Counselling services is one of the most critical determinants of health seeking attitude and behavior of people. This is more likely in respect of HIV testing and counselling services which is often compromised by factors such as perception and socio-cultural beliefs of the people. The responses regarding respondent's level of knowledge about HIV testing and counselling are presented in Table 4.2.

Table 4.2: Respondent's knowledge level about HTC Services

\begin{tabular}{|c|c|c|c|c|}
\hline Variables & Freq. & Percentage & $\overline{\mathbf{x}}$ & S.D \\
\hline \multicolumn{5}{|c|}{ Ever heard about HTC } \\
\hline Strongly Agree & 131 & 30.9 & 4.11 & 1.30 \\
\hline Agree & 217 & 51.2 & & \\
\hline Don't Know & 52 & 12.3 & & \\
\hline Disagree & 16 & 3.8 & & \\
\hline Strongly Disagree & 8 & 1.9 & & \\
\hline \multicolumn{5}{|c|}{ Knows a place to be tested for HIV } \\
\hline Strongly Agree & 175 & 41.4 & 4.04 & 1.23 \\
\hline Agree & 169 & 39.9 & & \\
\hline Don't Know & 51 & 12 & & \\
\hline Disagree & 21 & 5 & & \\
\hline Strongly Disagree & 7 & 1.7 & & \\
\hline \multicolumn{5}{|c|}{$\begin{array}{l}\text { Taking a test one week after unprotected } \\
\text { sex will tell HIV status }\end{array}$} \\
\hline Strongly Agree & 96 & 22.6 & 3.35 & 1.24 \\
\hline Agree & 131 & 30.9 & & \\
\hline Don't Know & 61 & 14.4 & & \\
\hline Disagree & 60 & 14.2 & & \\
\hline Strongly Disagree & 76 & 17.9 & & \\
\hline
\end{tabular}

Source: Field Work, 2018

Table 4.2 represents the analysis of the responses regarding the knowledge level of the youth on HIV Testing and Counselling (HTC). Majority of the respondents ( $\overline{\mathbf{x}}=4.11 ; \mathrm{SD}=1.3$ ) indicated majority of the respondents had heard about HTC while the responses from the respondents less dispersed from the mean. It was also evident that a few of the respondents 24 (5.7\%) had never heard about HTC while $12.3 \%$ were indifferent about their response. 
In terms of knowing a place to go for HTC, the calculated mean shows that most of the respondents $(\overline{\mathrm{x}}=4.11 ; \mathrm{SD}=1.3)$ knew where to go for HIV testing and counselling whiles there was less dispersion from the mean. It was interesting as it came to light that, some of the respondents $28(6.7 \%)$ displayed their ignorance of the place to go for HTC.

Finally, on the question about taking HIV test one week after having unprotected sex to tell one's HIV status, over half of the respondents had the answer correct $(\bar{x}=3.35$; $\mathrm{SD}=1.24)$. Hence, although most of the respondents had ever heard about HTC and knew the place to go for HTC, however about two-fifth of the respondents 136 (32.1\%) were ignorant about the fact that it is highly impossible for one to know his/her HIV status within one week of having unprotected sexual intercourse.

Again, from the table, the general mean of the respondents' knowledge level on HTC services was determined to be high (general mean=3.81). This is an indication that majority of the respondents had knowledge about HTC services.

\section{Extent of Utilization of HTC Services by Youth}

The second objective of the study was to assess the extent of use of HIV Testing and Counselling by the youth. The first part of this objective, the demographic background of the respondents influencing their decision to undertake HIV test was determined. The results are presented in Table 4.3 . 


\begin{tabular}{|c|c|c|c|c|c|}
\hline \multirow{3}{*}{ Variables } & \multirow{2}{*}{\multicolumn{5}{|c|}{ Have ever been tested for HIV }} \\
\hline & & & & & \\
\hline & Agree $(\mathrm{N}, \%)$ & Disagree (N, \%) & $\begin{array}{l}X^{2} \\
\text { value }\end{array}$ & df & Syn \\
\hline Sex & & & 3.84 & 1 & 0.05 \\
\hline Male & $60(56.6)$ & $147(46.2)$ & & & \\
\hline Female & $46(43.4)$ & $171(53.8)$ & & & \\
\hline Age & & & 17.64 & 2 & 0.00 \\
\hline $15-19$ & $51(48.1)$ & $221(69.5)$ & & & \\
\hline $20-24$ & $55(51.90$ & $97(30.5)$ & & & \\
\hline Place of Residence & & & 8.63 & 2 & 0.01 \\
\hline Rural & $69(30.1)$ & $158(81.0)$ & & & \\
\hline Urban & $160(69.9)$ & $37(19.0)$ & & & \\
\hline Education Level & & & 1.99 & 3 & 0.85 \\
\hline None & $12(11.3)$ & $27(8.8)$ & & & \\
\hline Primary & $9(8.5)$ & $20(6.3)$ & & & \\
\hline JHS & $46(43.4)$ & $145(45.6)$ & & & \\
\hline SHS and Above & $39(36.8)$ & $126(39.6)$ & & & \\
\hline Marital Status & & & 11.97 & 5 & 0.04 \\
\hline Single & $166(52.2)$ & $38(35.9)$ & & & \\
\hline Married & $6(1.9)$ & $3(2.8)$ & & & \\
\hline Divorced & $2(0.1)$ & $2(1.9)$ & & & \\
\hline Separated & $3(0.1)$ & $3(2.8)$ & & & \\
\hline Widowed & $26(8.2)$ & $17(16.0)$ & & & \\
\hline In a Relationship & $115(36.2)$ & $32(30.2)$ & & & \\
\hline Living Arrangement & & & 8.08 & 5 & 0.15 \\
\hline Alone & $18(17.0)$ & $45(14.2)$ & & & \\
\hline With parents & $52(49.1)$ & $179(56.2)$ & & & \\
\hline With friends & $3(2.8)$ & $7(2.2)$ & & & \\
\hline With other relatives & $20(18.9)$ & $68(21.4)$ & & & \\
\hline With spouse & $13(12.3)$ & $19(6.0)$ & & & \\
\hline
\end{tabular}

\section{Source: Field Work, 2018}

Table 4.3 shows that only 106 (25\%) of the respondents reported to have ever taken an HIV test before the study. Over two-third of the respondents 318 (70.4\%) had never been tested for HIV. The Chi-Square value was 3.84 with an asymptotic significance value of 0.05 and 1 degree of freedom. This implies a significant relationship between sex and having been tested for HIV. The distribution by age indicated that those who had ever taken HIV test were high among the youth aged 20-24 (51.9\%) and low at 48.1\% among 15-19 years old. HIV testing among the sampled youth therefore appreciated with age: the older the person, the more the likelihood of getting tested for the virus. This assertion is confirmed by the Chi-Square value which was 17.64 with an asymptotic significance value of 0.00 and 2 degree of freedom. This implies a significant relationship between age and having been tested for HIV.

In terms of place of residence, majority of respondents who had been tested lived in urban places (69.9\%) while a few (30.1\%) lived in the rural. Youth who have Junior High School (J.H.S.) education (43.4\%) were more likely to have taken HIV test as compared to those who have not have Senior High School (S.H.S.) education (36.8\%) and above. Moreover a few 
respondents who have had no formal education $(11.3 \%)$ had taken the HIV test. The ChiSquare value run was 0.01 with an asymptotic significance value of 0.85 and 3 degree of freedom. This implies that there is significant relationship between level of education and having been tested for HIV.

The table also indicated that most of the respondents who had taken an HIV test, there were more single people (52.2\%) than those who were in a relationship (36.2\%), widowed (8.2\%), married (1.9\%), separated $(0.1 \%)$ and divorced $(0.1 \%)$. The Chi-Square value was 11.97 with an asymptotic significance value of 0.04 and 5 degree of freedom. This implies a significant relationship between one's marital status and having been tested for HIV.

Lastly, with regards to living arrangement, almost half of the respondents who had tested for HIV lived with their parents $52(49.1 \%)$ while those who lived with their friends $3(2.8 \%)$ were the least to get tested. The Chi-Square value run was 8.08 with an asymptotic significance value of 0.15 and 5 degree of freedom. This implies that there is significant relationship between one's living arrangement and having been tested for HIV.

To further explore the extent of utilization of HTC by the youth, three questions were asked. The questions were to find out whether respondents had been tested within the last twelve months, offered counselling before the test was taken and also whether they went back for their results. The results is shown in Table 4.4

Table 4.4: Utilization of HTC Services

\begin{tabular}{|c|c|c|c|c|}
\hline Variables & Frequency & Percentage & $\overline{\mathbf{x}}$ & S.D. \\
\hline \multicolumn{5}{|c|}{ Tested for HIV within the last 12 months } \\
\hline Strongly agree & 16 & 15.8 & 3.20 & 1.30 \\
\hline Agree & 40 & 39.6 & & \\
\hline Don't know & 4 & 4.0 & & \\
\hline Disagree & 32 & 31.7 & & \\
\hline Strongly disagree & 9 & 8.9 & & \\
\hline \multicolumn{5}{|c|}{ Offered pre-counselling before the test } \\
\hline Strongly agree & 15 & 15.2 & 3.30 & 1.23 \\
\hline Agree & 42 & $42 . .4$ & & \\
\hline Don't know & 7 & 7.1 & & \\
\hline Disagree & 28 & 28.3 & & \\
\hline Strongly disagree & 7 & 7.1 & & \\
\hline \multicolumn{5}{|c|}{ Obtained results after test } \\
\hline Strongly agree & 17 & 16.8 & 3.35 & 1.24 \\
\hline Agree & 51 & 50.5 & & \\
\hline Don't know & 3 & 3.0 & & \\
\hline Disagree & 24 & 23.8 & & \\
\hline Strongly disagree & 6 & 5.9 & & \\
\hline
\end{tabular}

\section{Source: Field work, 2018}

Table 4.4 shows the results of respondents' utilization of HTC services. The mean and the standard deviation obtained ( $\overline{\mathbf{x}}=3.2$; SD 1.30) indicate that most of the respondents agree with the statement with less dispersion of the responses around the mean. Also, among those who had been tested most of them $(\overline{\mathbf{x}}=3.3 ; \mathrm{SD}=1.23)$ indicated they were taken through pre-test counselling before the test was carried out. Finally, out of those who had ever taken HIV test, a 
significant number of them $(\overline{\mathbf{x}}=3.35$; SD 1.24) showed agreement with the statement with less dispersion around the mean.

Similarly, Chi-square analysis of taking HIV test within the last twelve months by personal characteristics of respondents are summarized in Table 4.5.

Table 4.5: Chi-square analysis of respondents taking HIV test within the last twelve months by personal characteristics of respondents

\begin{tabular}{lllll}
\multicolumn{4}{c}{ personal characteristics of respondents } \\
\hline Personal Characteristics & $\mathbf{x}^{2}-$ value & df & $\mathbf{N}$ & Sign \\
\hline Sex & 0.48 & 5 & 424 & 0.469 \\
Age & 10.993 & 10 & 424 & 0.358 \\
Place of Residence & 23.786 & 10 & 424 & 0.008 \\
Formal Educational Level & 25.883 & 25 & 424 & 0.414 \\
Marital Status & 43.952 & 25 & 424 & 0.011 \\
Living Arrangement & 49.863 & 25 & 424 & 0.002 \\
\hline df= degree of freedom & & & &
\end{tabular}

Source: Field Work, 2018

From Table 4.5, the chi-square analysis shows that there were no significant relationship between sex, age, level of formal education and taking HIV test within the last twelve months. This is an indication that the socio-demographic variable; sex, age and level of formal education do not significantly affect one's tendency to take an HIV test within the last twelve months. On the other hand, the variables; place of residence, marital status, living arrangement had significant relationship. This shows that the desire of the respondents to undertake HIV test within the last twelve months was significantly influenced by the place of residence, marital status and living arrangement.

Table 4.6: Chi-square analysis of Respondents offered pre-counselling before test by characteristics of respondents

\begin{tabular}{lllll}
\hline Personal Characteristics & $\mathbf{x}^{2}-$ value & df & $\mathbf{N}$ & Sign. \\
\hline Sex & 2.620 & 5 & 424 & 0.758 \\
Age & 8.739 & 10 & 424 & 0.557 \\
Place of Residence & 26.297 & 10 & 424 & 0.003 \\
Educational Level & 23.671 & 25 & 424 & 0.538 \\
Marital Status & 25.487 & 25 & 424 & 0.435 \\
Living Arrangement & 17.528 & 25 & 424 & 0.862 \\
\hline
\end{tabular}

Source: Field Work, 2018

Table 4.6 shows the relationship between personal characteristics of respondents and being offered pre-counselling services at the HTC centre. From the calculated chi-square values in the table, it is clear that, sex, age, level of education, marital status had no significant relationship with pre-counselling service. This means that respondents who were given pre-test counselling were not influenced by their sex, age, level of formal education and marital status.

It is however clear from the results displayed in the table that, place of residence was the only demographic variable that had significant relationship with being offered pre-test counselling. This implies that where the individual lives (that is whether rural or urban) has significant impact on pre-counselling services at the HTC centre. 


\section{Introduction}

\section{DISCUSSION OF FINDINGS}

This chapter presents a discussion of the findings of the study, as outlined in the objectives of the study. The study seeks to examine factors that contribute to HIV Testing and Counselling utilization among the youth of the Tarkwa-Nsuaem and Fanteakwa Districts of Ghana. The study explored youths' knowledge and usage of HTC using the health belief model. The discussions of the findings were done under the following major headings:

- Knowledge of HIV Testing and Counselling Service

- Utilization of HIV Testing and Counselling

- Constructs of the Health Belief Model and HTC

\section{Knowledge of HIV Testing and Counselling Service}

Knowledge of HIV testing and counselling services is likely to influence the respondents' attitude and behavior towards HIV and AIDS in terms of patronage of HIV testing and counselling. It was found from the study that as high as $80 \%$ respondents had heard about HIV Testing and Counselling (HTC) and over 80\% knew where to seek for HIV Testing and Counselling. This is very significant as it shows that awareness of HTC is almost prevalent among the respondents. This finding generally conforms to results from earlier studies in Nigeria, Ethiopia and Tanzania by Zelalem, et al, (2013) and Sanga, Kapanda, Msuya \& Mwangi (2015). The high knowledge of awareness of HTC could be attributed to an increase in access to electronic-media. There has been an increased number of radio and television stations and also internet access across many places in Ghana in recent times. For this reason, individuals could easily get information on HTC from these radio stations and the internet. Since, media and internet platforms have been identified as vibrant sources of information about HIV testing and counselling services, there is therefore the need to intensify education about HIV testing and counselling services via the mass media and internet.

\section{Utilization of HIV Testing and Counselling}

The second objective of the study concerns the extent to which youth in the Tarkwa-Nsuaem and Fanteakwa District utilize HIV Testing and Counselling services. Though results from the study indicates that more than $80 \%$ of respondents did not deny that they knew about HTC and where to obtain the services, it was regrettable that only one out of four of the respondents (25\%) had utilized HTC service to find out their HIV status at the time of the study. This findings is similar to that of Fikadie, Badimo and Alamrew (2014) where $37.8 \%$ of the respondents had utilized HTC but contrary to the finding of Tsesay, Edris and Meseret (2011) which recorded over 50 percent of respondents who had utilized HTC. Again, it is interesting to note that majority of the respondents agreed that knowledge about HTC services and places to obtain such services is important but attributed their inability to utilize such services to the four main factors. These factors are one, HIV testing and counselling facilities are not client friendly; two lack of trust among the respondents for the workers at the HTC facilities; three the societal perception of sexual promiscuity associated with those who regularly utilize HTC services and four, the socio-cultural belief among the respondents that once, their status is known, their well-being "would start deteriorating. It will therefore not be wrong to state that knowledge of HTC alone is insufficient to promote optimum utilization of HTC.

From the study more than 50 percent of males had tested for HIV as compared to the $43.4 \%$ females. This is similar to other studies by Fikadie et. al. (2014) which also had more males testing for HIV than the females. Similarly, it is also interesting to note that even when the respondents mastered courage to utilize HTC services, more males than females tested for HIV. This development accentuates the belief that women are more concerned about the sanctity and society perception associated with sexual life. This phenomenon gives credence to 
apparently inability to utilize the HTC services in view of the reasons mentioned above, especially among the female respondents.

Further findings from the study show that out of the total number that had been tested for HIV, $57.6 \%$ said they were given counselling before their blood was drawn for the test. It further showed that about $67.3 \%$ did obtain their results after the test. The findings throw more light on the widely held perception among the respondents that HTC facilities are not client friendly. This situation is alarming, since it has the tendency to make justification for inability to utilize the HTC services stronger and even erodes the confidence respondents have in the health workers at the facilities. This result is contradictory to what contained in the HIV Sentinel Survey report of 2010 (Chris-Cola, 2012 citing GSS, 2010).

\section{SUMMARY, CONCLUSION AND RECOMMENDATIONS}

The general objective of the study was to examine the factors that contribute to HIV Testing and Counselling (HTC) utilization, among youth in Tarkwa-Nsuaem and Fanteakwa Districts of Ghana in the light of the Health Belief Model (HBM).

\section{Summary}

This study sought to examine HIV Testing and Counselling among the youth through the Health Belief Model. The study had the objective to examine the knowledge level of the youth on HTC and again, to assess the extent to which the youth of Tarkwa and Fanteakwa District Utilize HTC Services. Lastly, to determine how the constructs of the Health Belief Model relates to HTC participation.

Based on these objectives a sample size of 424 youth in the Tarkwa-Nsuaem and Fanteakwa Districts within the ages of 15-24 years was selected and responses were elicited from them through the use of questionnaires. The findings revealed from the study are as follows:

i. A large percentage of over $80 \%$ of the sampled youth admitted having heard about HTC and also knew where to go for HIV testing.

ii. The study also revealed that about $63 \%$ of the respondents were ignorant of the fact that it was highly impossible for someone to know his/her HIV status especially through Antibody test if he/she takes the test one week after having unprotected sex.

iii. It also came out from the study that as little as $25 \%$ had ever taken HIV test at the time of the study. And out of those who had taken the test, more males (56.6\%) had taken the test as compared to the (43.4\%) females.

iv. It was also reported that out of those who had ever taken the test $57.1 \%$ indicated to have been given pre-counselling service before the test.

v. Finally, it came to light that most urban dwellers (69.9\%) seek HTC services than the rural dwellers (30.1\%).

\section{Conclusion}

The threat that HIV and AIDS poses to infected persons, the affected families and the nation cannot be under estimated. When no treatment is applied or if left to take its natural course, this condition can ravage the lives of individuals most dear to us and could lead to the death of our children, fathers, mothers, brothers, wives, uncles and aunties. For this reason, no effort must be spared to find best ways or strategies to get vulnerable populations such as the youth to know their HIV status, since this is the only gateway to treatment and healthy life for all infected persons. It must be stated that the low patronage of HTC as revealed by the study from the respondents of Tarkwa-Nsuaem and Fanteakwa is a wake-up call to all stakeholders, if the 90-90-90 target set by UNAIDS and also the Ghana AIDS Commission is to become a reality and not just a mere dream. In spite of all the efforts that may be put in place to get $90 \%$ of persons 
living with HIV and AIDS to know their status by the year 2020, it has become even more important to understand the complexity of decisions that the youth go through regarding HIV Testing and Counselling.

\section{Recommendations}

To enhance HTC services, the following recommendations are proposed based on the findings of the study for practice and further research:

\section{Ghana Health Service/District Health Directorate}

i. It is recommended that public health education programmes on HTC be intensified for more people to realize the dying need for them to know their HIV status.

ii. Stakeholders on HIV and AIDS such as the government, the Ministry of Health should attach celebrities such as musicians, movie actors and well-known footballers to know your HIV status campaign programmes. This will help increase the uptake of HIV testing and counselling as individual, especially the youth see these celebrities as role models.

\section{Policy Makers}

i. There is the need for government to establish more HTC centres to add to the existing ones in order to bring HTC service closer to the youths.

ii. The development of self-testing kits for HIV is being advocated as it removes the issue of confidentiality. This is similar to what is obtained in self-pregnancy testing using the serology based test kit. However, these test kits should be put at places where one could pick at will without any confrontation from any other person. This can later be followed by counselling at an HTC centre if the person discovers that he/she is HIV positive.

iii. The various departments and agencies under the ministries, non-governmental organisations, the media, chiefs, the clergy, opinion leaders should spearhead the promotion of health especially HTC during their yearly activities and durbars.

\section{Counsellors or Health Personal at HTC centre}

i. Counsellors should attend more refresher courses or workshops to update their knowledge on HTC so that adequate information could be disseminated to the youth who may need their services.

ii. Counsellors should re-organise facilities at the counselling centres to provide a friendlier atmosphere full of privacy to the youth.

\section{Suggestions for Further Research}

The study is a quantitative survey; however, not every aspect of HTC could be exhausted by the study. A further study on this regard using qualitative approach would be appropriate to give it more insight into utilization of HIV. Also further studies could also be conducted to find out the attitude of the youth towards persons living with HIV and AIDS.

\section{References}

Badu-Nyarko, S.K. (2011). Basic Research Methods in Social Science. Accra: BB Manufacturing Ltd.

Christ-Koka, E. (2012). Factors affecting HIV counselling and testing among students in the Ho Municipality. MSc Dissertation: University of Ghana. Retrieved 12/04/2018 fromhttp://dl,handle.net/123456789/5571

Downing-Matibag, T. M., \& Geisinger, B. (2009). Hooking up and Sexual Taking Among College Students: A Health Belief Model Perspective, SAGE.

Fiaveh, D.Y., \& Lakas, H.M. (2011). Male Perspective on Condom Use: Context of STI/HIV prevention in the University of Ghana Community. Journal Public Epidemiology, 11(1):7-27

Fikadie, G., Bedino, M., \& Alamu, Z. (2014). Prevalence of Voluntary Counselling and Testing Utilization and its Associated Factors among Bahirdar University Studies. Journal of Advancy in Preventive Medicine, 906107, 1-9 
GAC/MOH, (2014). HIV sentinels survey report and National prevalence. AIDS estimates report. Accra: GAC

Ghana Statistical Service (GSS), (2010). Ghana Demographic and Health Survey, Accra: GSS

GHS/MOH/UNFPA (2005).Training Manual for health care providers in Ghana (1 ${ }^{\text {st }}$ ed). Accra: GHS/MOH/UNFPA.

King, R. (1990). Sexual Behavioural Change For HIV: Where Have Theories Taken Us? Geneva: UNAIDS.

Kunsu, R. (2010). An assessment of knowledge on VCT for HIV among adolescents in SHSs in the Nadowli district of the Upper West Region of Ghana using HIV/AIDS and VCT education. Retrieved from http://www.reproductivehealth-journal.com/content on 24/02/2018.

Lewis, S., \& Colbert, F. (2006). Socio-cultural impact of HIV/AIDS in Africa. Lagos: Zak press.

Phiri, W. and Phiri, G.G. (2016). Factors affecting ICT Implementation in selected secondary schools in Chipata district. . International Journal of Multidisciplinary Research and Development, Vol. 3. Issue 10 October pp. 161-175.

Rosanthal, S., Griffith, J., Succop, P., Biro, F., Lewis, L., DeVellis, R. (2002). The relationship between STD locus of control and STD acquisition among adolescent girls. Adolescence, 37, 83-92.

Sanga, Z., Kapanda, G., Msuya, S., \& Mwangi, R. (2015). Factors influencing the uptake of Voluntary HIV Counseling and Testing among secondary school students in Arusha City, Tanzania: a cross sectional study. BMC Public Health, 15(1). Retrieved from: https://doi.org/10.1186/s12889-015-1771-9 on 22/3/2018

Sarmah , H. K., Bora-Hazarika, B., \& Choudhury, G. (2013). An investigation on effect of bias on determination of sample size on the basis of data related to the students of schools of Guwahati. International Journal of Applied Mathematics \& Statistical Sciences (IJAMSS), 2 (1), 33-48

Tanye, V.K. (2013). Exploring the attitude, knowledge and experience of the youth towards HIV counselling and testing. MPhil Thesis: University of Ghana. Retrieved April 19, 2016 from ugspace.ug.edu.gh.8080/xmlui/111/5928 or http://hdl. Handle.net/123456789/5928

Tsegay, G., Edris, M., \& Meseret, S. (2011). Assessment of voluntary counseling and testing service utilization and associated factors among Debre Markos University Students , North West Ethiopia : a cross-sectional survey in 2011.

UNAIDS, (2016). AIDS in Africa. Retrieved from www.unaids.org on 2/2/2018

WHO, (2012). Factsheet on HIV/AIDS prevalence. Retrieved from http://www.who.int/hiv/pub/HCT/pitc2007/en/index.htm on 12/01/2018.

Yahaya, L., Jimoh, A., \& Balogun, O. (2010). Factors Hindering Acceptance of HIV/AIDS Voluntary Counseling and Testing (VCT) among Youth in Kwara State, Nigeria. African Journal of Reproductive Health, 14(3), $159-164$.

Zalalem, A., Yalew, A., Shiferaw, Y., Birhan, W., Mathewose, B., \& Tachebele, B. (2013). Knowledge, attitude and practice among university students in North West Ethiopia: a cross sectional study", BMC Health, 10(26). 